\title{
Gas-Phase Reactivity of Ruthenium Carbonyl Cluster Anions
}

\author{
Matthew A. Henderson, Samantha Kwok, and J. Scott McIndoe \\ Department of Chemistry, University of Victoria, Victoria, British Columbia, Canada
}

Partially-ligated anionic ruthenium carbonyl clusters react with alkenes, arenes, and alkanes in the gas phase; the products undergo extensive $\mathrm{C}-\mathrm{H}$ activation and lose dihydrogen and carbon monoxide under collision-induced dissociation conditions. Triethylsilane and phenylsilane are also reactive towards the unsaturated clusters, and oxygen was shown to rapidly break down the cluster core by oxidative cleavage of the metal-metal bonds. These qualitative gas-phase reactivity studies were conducted using an easily-installed and inexpensive modification of a commercial electrospray ionization mass spectrometer. Interpretation of the large amounts of data generated in these studies is made relatively straightforward by employing energydependent electrospray ionization mass spectrometry (EDESI-MS). (J Am Soc Mass Spectrom 2009, 20, 658-666) (c) 2009 Published by Elsevier Inc. on behalf of American Society for Mass Spectrometry

$\mathrm{T}$ There are many examples of reactions between molecules and metal cluster ions in the gas phase, and the area has been well reviewed [1, 2]. Of intense current interest are those systems in which catalytic reactions (homogeneous or heterogeneous) are modeled [3, 4]. The information gleaned from these studies is particularly advantageous in systems where little or nothing is known about reactivity. Interest in the area stems from the fact that the chemistry of highly reactive, metallic nanoparticles is fundamentally difficult to study, and it is high surface area metals and metal oxides that are responsible for the most industrially important heterogeneous catalytic reactions. Any means of gaining insight into the mechanism of these reactions may prove useful in designing more efficient and more selective catalysts. The absence of surfaces, solvents, and counterions make the gas phase a considerably less complicated environment than that found in solution. Just how good the correspondence is between gas-phase and solution results is subject to active debate [5-7], but there is little argument that the gas phase benefits from the reduction in the number of variables, especially when dealing with complicated systems. The gas-phase reactivity of a wide variety of partially ligated clusters have been studied, including oxides [8-11], hydrides [12], sulfides [13-15], carbides [16], carbenes [17], phosphines [18]. and even some mixed species $[19,20]$. However, for the most part, the extent of ligation is low and, correspondingly, so is the relevance to solution chemistry. Homogeneous catalysis is generally performed under conditions that are relatively mild and in which the catalysts maintain a (near)

Address reprint requests to Dr. J. S. McIndoe, Department of Chemistry, University of Victoria, P.O. Box 3065, Victoria, BC V8W 3V6, Canada. E-mail: mcindoe@uvic.ca complete coordination sphere, so the comparison with nearly naked gas-phase metal clusters is somewhat tenuous (though interestingly, may more closely approximate the conditions of heterogeneous catalysis, which frequently involves unligated metal particles on a surface) [21, 22].

Some work has also been done on partially ligated carbonyl clusters; an early paper by Ridge [23] demonstrated that the reactivity of $\left[\mathrm{Co}_{2}\right]^{+}$and $\left[\mathrm{Co}_{2}(\mathrm{CO})\right]^{+}$ towards $\left(\mathrm{CH}_{3}\right)_{2} \mathrm{CHBr}$ was quite different, with $\left[\mathrm{CO}_{2}\right]^{+}$ breaking the alkyl bromide into $\mathrm{C}_{3} \mathrm{H}_{6}$ and $\mathrm{HBr}$ and the $\left[\mathrm{Co}_{2}(\mathrm{CO})\right]^{+}$causing $\mathrm{C}-\mathrm{H}$ bond activation. Another notable example by Ridge demonstrated that in a Fourier transform ion cyclotron resonance mass spectrometer (FTICR-MS), partially ligated cationic transition-metal carbonyl clusters generated by electron ionization reacted readily with cyclohexane or 1-hexene, but that anionic clusters generated by electron capture failed to react [24]. Transition-metal carbonyl cluster anions provide excellent electrospray ionization mass spectra (ESIMS), and collision-induced dissociation (CID) can be used to selectively remove some or all of the $\mathrm{CO}$ ligands from the metal core [25]. We have used these properties in the past to study the reactivity of $\left[\mathrm{CoRu}_{3}\right]^{-}$with methane and hydrogen using an FTICR-MS instrument [26]. In this study, we describe some similar experiments, this time with a simple modification of a commercial Q-TOF instrument to allow gas-phase reactivity. The experimental setup is sufficiently trivial (and the modifications readily reversible) that it can be reproduced by a chemist without special expertise in instrument building (provided, of course, they had access to an ESI mass spectrometer).

We found that the anionic cluster $\left[\mathrm{H}_{3} \mathrm{Ru}_{4}(\mathrm{CO})_{12}\right]^{-}$ (1), after suitable activation via CID, reacted readily with a variety of molecules in the gas phase including
(C) 2009 Published by Elsevier Inc. on behalf of American Society for Mass Spectrometry. $1044-0305 / 09 / \$ 32.00$

doi:10.1016/j.jasms.2008.12.006
Published online December 13, 2008 Received November 12, 2008 Revised December 2, 2008 Accepted December 2, 2008 
alkenes, arenes, alkanes, silanes, and oxygen. The degree of unsaturation (CO loss) required to induce reactivity varied greatly, depending on the substrate employed. Spectra are complicated, especially given the dramatic changes evident as the amount of CID energy is altered, but interpretation was made relatively straightforward by application of EDESI-MS.

\section{Experimental}

$[\mathrm{PPN}]\left[\mathrm{H}_{3} \mathrm{Ru}_{4}(\mathrm{CO})_{12}\right]$ was made by a published method [27]. Cyclopentene, 1-hexene, toluene, pentane, chlorobenzene, and triethylsilane were purchased from Aldrich and used as supplied (the toluene and pentane were HPLC grade). Phenylsilane was prepared via $\mathrm{LiAlH}_{4}$ reduction of trichlorophenylsilane (Aldrich, Oakville, Canada). Oxygen and nitrogen (99.99\%) was purchased from Airgas (Calgary, Canada). Electrospray ionization mass spectra were collected using a Micromass QTOF micro instrument. Capillary voltage was set at $2900 \mathrm{~V}$, source and desolvation gas temperatures were at 50 and $100{ }^{\circ} \mathrm{C}$, respectively. The $[\mathrm{PPN}]\left[\mathrm{H}_{3} \mathrm{Ru}_{4}(\mathrm{CO})_{12}\right]$ salt was dissolved in dichloromethane and was infused via syringe pump at 5-10 $\mu \mathrm{L} \mathrm{min}^{-1}$. EDESI-MS(/MS) spectra were collected using published procedures [28, 29], and processed using the program EDit [30]. The cone gas inlet was spliced to allow the introduction of a reactive gas, either by substituting the nitrogen for another gas or by the simple expedient of allowing the nitrogen to pass through a vial containing a volatile liquid and entraining the vapor of the compound of interest (Figure 1). The extra apparatus required on our instrument consisted of a glass vial, a septum, two stainless steel needles, and some flexible plastic tubing, copper tubing, and an alternative source housing built to receive the reactive gases (see supporting information, which can be found in the electronic version of this article, for a photograph of all modifications). All modifications were to the front of the instrument, leaving the inner workings of the mass spectrometer untouched. This setup can be facilitated on any similar instrument with inexpensive and readily available materials.

The reactive gas was introduced by passing a stream of nitrogen through the appropriate liquid and directing the saturated gas through the cone gas port. The flow rate was $\sim 15 \mathrm{~L} \mathrm{~h}^{-1}$, compared with a desolvation gas flow rate of $100 \mathrm{~L} \mathrm{~h}^{-1}$. Automation of the mass spectrometer software to carry out the EDESI experiments (ramping of the cone or collision voltage) was achieved using the program Autohotkey (freely available from http:/ /www.autohotkey.com/).

\section{Results and Discussion}

Ion-molecule reactions have been probed extensively using mass spectrometry [31], and a wide variety of experimental configurations have been employed, for this purpose, of varying degrees of sophistication. For reactions on an extended timescale, a trapping mass spectrometer such as an FTICR-MS or a quadrupole ion trap is generally used. Modifications of instruments to enable the study of gas-phase reactions can be quite elaborate and require considerable rebuilding and customization. Chen, for example, has built triple quadrupole instruments with 24-pole reaction chambers to facilitate polymerization reactions in the gas phase [32]. Gerlich uses a 22-pole ion trap to study a wide range of ion-molecule reactions [33]. O'Hair has used a modified ion trap instrument to probe a variety of reactions [34], many with specific relevance to organometallic and

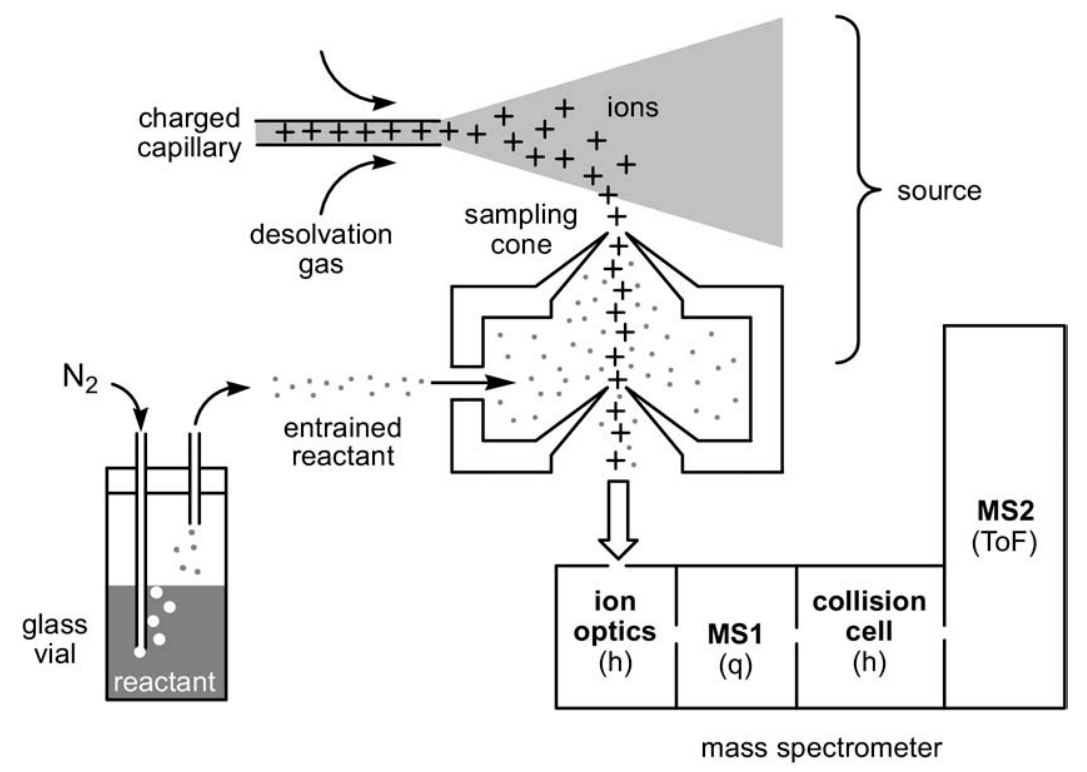

Figure 1. Schematic illustrating the point at which the reactive gas is introduced to the instrument. The reactive gas is either a volatile liquid entrained in a stream of nitrogen gas (as shown) or gas supplied from a cylinder. 
catalytic chemistry. Schroeder and Schwarz use a triple quadrupole where reactive gases are introduced to the collision cell for the purposes of ion-molecule reactions $[35,36]$.

For the practicing organometallic chemist to apply gas-phase reactivity to their own compounds, the barrier to performing these experiments must be low. Any modification to an instrument (particularly in light of the fact that most mass spectrometers are a widely shared resource) should be easy to perform, require no special tools, expertise or apparatus, cost practically nothing, and be readily reversible (or at least not interfere with the routine operation of the instrument). There should also be a way to interpret the results from the experiments in a straightforward way that does not require separate examination of a large number of spectra. This article details simple ways of achieving both of these ends.

A conventional electrospray ionization (ESI) source [37] is designed to completely dehydrate a protein in a fraction of a second using a combination of high temperature, high flow rate of desolvating nitrogen gas, and differential pumping. However, these sorts of conditions are considerably more robust than those required to obtain satisfactory spectra of organometallic species [38]; often, a room-temperature source and desolvation gas are perfectly sufficient when spraying solvents such as dichloromethane ("coldspray" sources [39] operate at even lower temperatures) [40]. As a result, a typical commercial instrument is greatly overspecified for the purposes of desolvating organometallic complexes, and this fact may be exploited in adapting the machine for the purposes of conducting ionmolecule reactions. The differentially-pumped region at the front end of the instrument is already used to carry out collision-induced dissociation (CID) of ions, as the mean free path length of the ions becomes sufficient that ion-molecule collisions can be made energetic enough to cause ion fragmentation [41]. However, (partial) replacement of the collision gas (dinitrogen) with an alternative gas permits ready investigation of ion reactivity. The Z-spray source used on Micromass instruments allows introduction of what is described as "cone gas" at precisely the region of interest; cone gas is simply an auxiliary stream of nitrogen that may be switched on at a user-selected flow rate to enhance the desolvation capabilities of the source. The small modification is transformative in terms of turning the instrument from an analytical tool into a laboratory capable of studying the reactivity of any gas-phase charged species. Similar experimental arrangements have been reported elsewhere for slightly different purposes; Posey was able to heavily solvate transition metals in the gas-phase by introducing an auxiliary source of solventladen dinitrogen at the electrospray source [42]. A variety of solvents, including DMSO and DMF, typically unsuitable for ESI-MS [43], could be vaporized and introduced to gas-phase ions for analysis in a tandem mass spectrometer [44]. The exact experimental details are not revealed, but since we are able to reproduce their results on our instrumental set-up suggests the two systems are likely to be similar. Posey's system was rediscovered by Vékey [45], who also used saturated curtain gas to generate heavily solvated ions ( 2 to 100 solvent molecules). Indeed, if the solvent is water, the experiment is even easier, as the source can simply be set up under "cold-flooding" conditions (low temperature, high sample flow rate, low desolvation gas flow rate) and ions, whether singly or multiply charged, can be observed as highly hydrated species [46, 47].

We are interested in investigating reactions with relevance to organometallic catalysis, especially for reactions that are resistant to spectroscopic analysis by other methods [48]. Transition-metal carbonyl clusters are a good example of just such a system, as these compounds lack diagnostic spectroscopic handles: ${ }^{1} \mathrm{H}$ NMR is usually uninformative due to the lack of protons; ${ }^{13} \mathrm{C}$ NMR requires isotopic enrichment even for pure compounds, and fluxional processes often render all ${ }^{13} \mathrm{CO}$ environments equivalent on the NMR timescale; IR spectroscopy, while good for fingerprinting, provides little informative structural detail on complicated systems [49]. Little is known about the reactivity of these compounds beyond observation of product distributions, and even here, the best-characterized products are those that form X-ray quality crystals. There is a real need for a rapid means to screen the reactivity of these compounds towards a wide range of substrates without recourse to tedious purification and full characterization.

The compound we chose to examine was the anionic ruthenium cluster $\left[\mathrm{H}_{3} \mathrm{Ru}_{4}(\mathrm{CO})_{12}\right]^{-}(\mathbf{1})$, prepared as the $\left[\mathrm{PPh}_{3} \mathrm{NPPh}_{3}\right]^{+}(\mathrm{PPN})$ salt [27]. Cluster $\mathbf{1}$ has several desirable features; it is easily prepared, charged (and hence highly amenable to analysis by ESI-MS), contains both hydride and carbonyl ligands (thus may undergo interesting reactivity involving both types of ligand), and is a catalyst for reactions including the water gas shift reaction [50,51], hydrogenation [52], and coupling reactions [53]. The parent compound, $\mathrm{H}_{4} \mathrm{Ru}_{4}(\mathrm{CO})_{12}$, is also a well-known catalyst for a range of similar transformations [54-57].

\section{Data Interpretation}

Fragmentation of ionic, even-electron coordination compounds under CID conditions is typically fairly straightforward. Neutral monodentate ligands that can be eliminated as stable molecules (L) are first to go, e.g., $\mathrm{CO}$, phosphines $\left(\mathrm{PR}_{3}\right)$, alkenes, dihydrogen, etc. Polydentate ligands are much more difficult to remove and are generally not eliminated as a single entity, instead rearranging and departing as separate, smaller molecules, sometimes in conjunction with other ligands. Formally anionic ligands can be lost from the metal center either as radicals, $X$. (with difficulty), or in combination with another ligand, $X Y$, in a reductive 
elimination (often a relatively low-energy process). For the most part, the product ion contains the metal, except in special circumstances where a ligand is identifiably the site at which the charge resides [58].

Interpreting the MS/MS data of coordination compounds is usually straightforward, especially when dealing with mononuclear metal complexes containing only a handful of ligands. The situation is, however, much more complicated for compounds of higher molecular weight, such as metal clusters, which frequently have a dozen or more ligands, and so choosing the appropriate conditions to get a representative spectrum containing all product ions is not feasible. Several spectra can do the job, but a more elegant solution is to collect data across the whole accessible range of fragmentation energies and present all of these spectra simultaneously as an energy-dependent contour map [59]. This type of presentation represents a three-dimensional (3D) surface in which collision energy and $m / z$ form the $x$ - and $y$-axes and ion intensity the $z$-axis. For example, the transition-metal carbonyl cluster 1 fragments in the source region of an ESI-MS with sequential loss of all 12 carbonyl ligands as carbon monoxide, and loss of two of the hydride ligands as dihydrogen, to generate $\left[\mathrm{HRu}_{4}\right]^{-}$ (Figure 2). The cone voltage represents the energy imparted to the ions via collision-induced dissociation (CID), and may be varied between 0 and $200 \mathrm{~V}$. As such, 201 unique spectra can be collected for each sample of interest, representing a substantial amount of data not easily depicted in a traditional format. It is also clear that to analyze any single cone voltage separately (three individual voltages are also shown in Figure 2) requires discarding information that may be had from the remaining voltages. In this example, data from 198 other voltages were ignored (accounting for $98.5 \%$ of the data) in the three separate 2D mass spectra, whereas all 201 voltages are concisely represented in the contour map. Loss of $12 \mathrm{CO}$ ligands is obvious and peak assignment is simple. At low cone voltages, the compound remains intact, but as the CID energy is increased all of the $\mathrm{CO}$ groups are removed sequentially. This map provides a baseline with which to assess the degree of gas-phase reactivity in subsequent experiments.

\section{Alkenes}

1-Hexene reacts readily with unsaturated clusters $\left[\mathrm{H}_{3} \mathrm{Ru}_{4}(\mathrm{CO})_{n}\right]^{-}$, generated from 1 via CID. The extent of reaction depends dramatically upon the degree of unsaturation; loss of three CO ligands results in appreciable reaction with one equivalent of 1-hexene, but further CID increases reactivity to the point where two and even three equivalents of 1 -hexene can be added to the cluster (Figure 3 contour plot). These reactions happen simultaneously with $\mathrm{CO}$ loss and significant loss of $\mathrm{H}_{2}$. Clusters adding one equivalent of 1-hexene $\left(\mathrm{C}_{6} \mathrm{H}_{12}\right)$ undergo extensive subsequent fragmentation via $\mathrm{CO}$ and $\mathrm{H}_{2}$ loss to the point that the final product ion is $\left[\mathrm{HRu}_{4} \mathrm{C}_{6}\right]^{-}$, indicating no less than seven dihydrogen (some of which may be eliminated as formaldehyde) molecules are lost from the cluster. This result implies

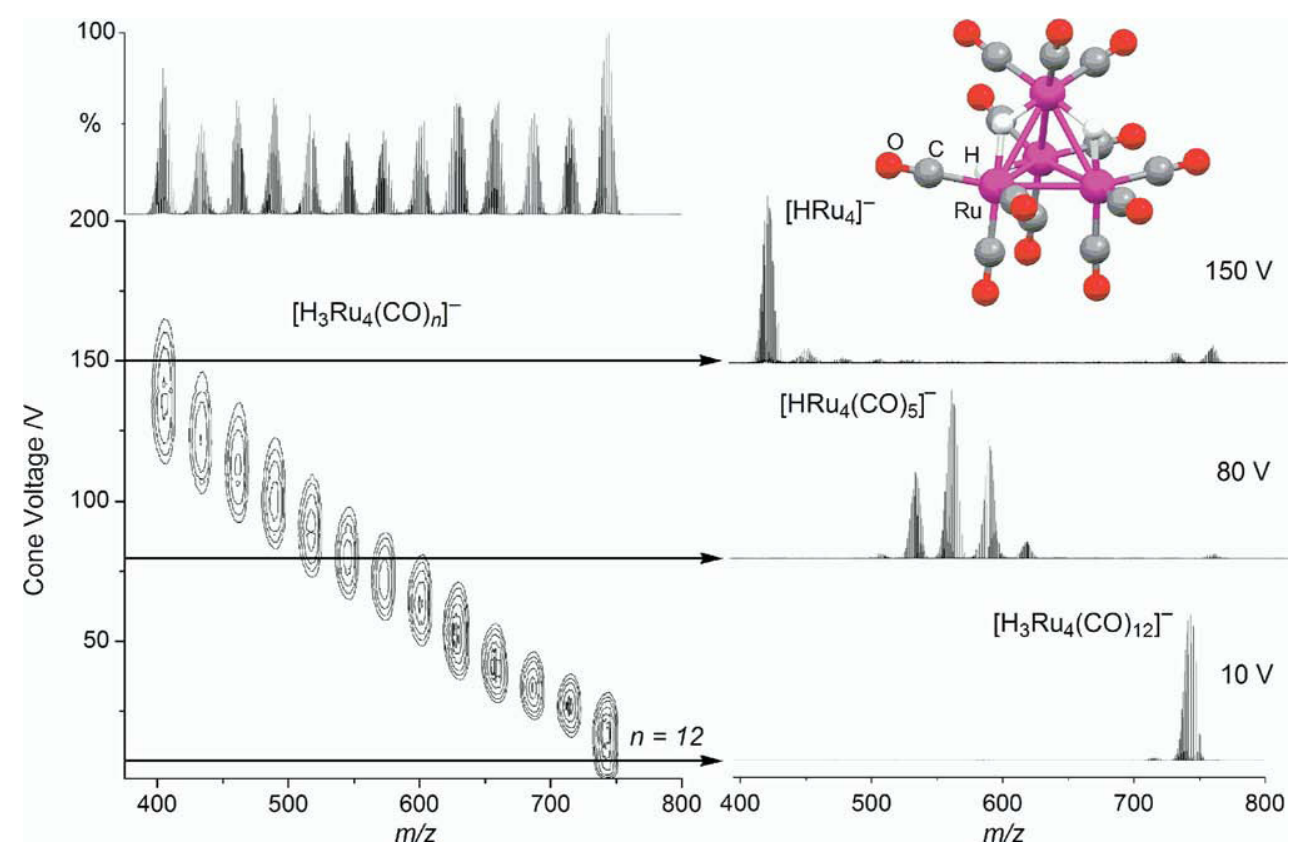

Figure 2. The left-hand contour plot of $\left[\mathrm{H}_{3} \mathrm{Ru}_{4}(\mathrm{CO})_{12}\right]^{-}$clearly shows the loss of twelve $\mathrm{CO}$ ligands as the cone voltage is increased. The three conventional mass spectra at the right provide snapshots of the ligand stripping process, at 10,80, and $150 \mathrm{~V}$; note the number of product ions missing from this portrayal. Inset: structure of the anionic ruthenium carbonyl cluster $\left[\mathrm{H}_{3} \mathrm{Ru}_{4}(\mathrm{CO})_{12}\right]^{-}$(1) [27]. The $\mathrm{Ru}$ atoms describe a tetrahedron; each $\mathrm{Ru}$ atom has three terminally-bound $\mathrm{CO}$ ligands and hydride ligands bridge three of the six $\mathrm{Ru}-\mathrm{Ru}$ bonds. 


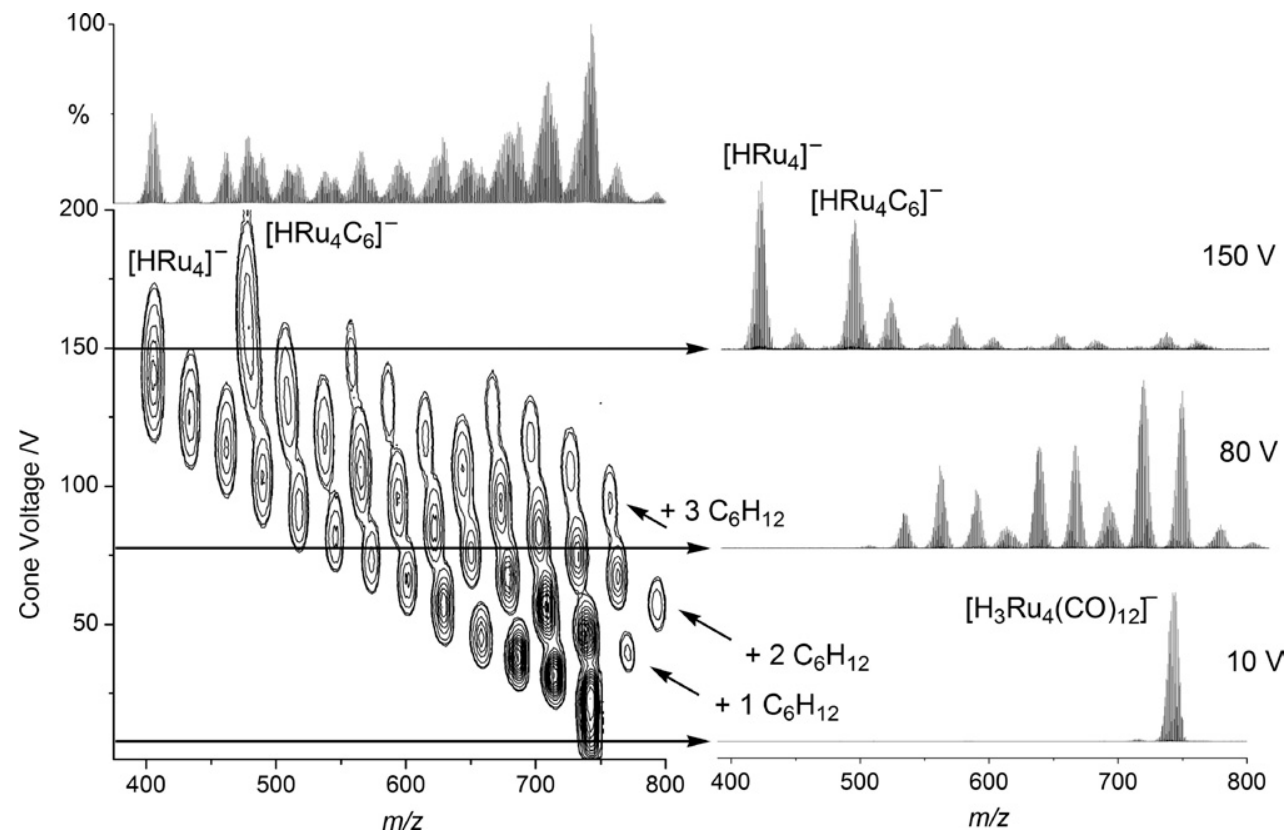

Figure 3. The negative-ion EDESI-MS of $\left[\mathrm{H}_{3} \mathrm{Ru}_{4}(\mathrm{CO})_{12}\right]^{-}$, collected in the presence of 1-hexene. Peak assignments are available in the supporting information. The conventional spectra clearly show the challenge inherent in interpreting MS/MS data at set cone voltages.

$\mathrm{C}-\mathrm{H}$ activation on a massive scale and is in keeping with observed intermolecular reactivity of completely naked metal clusters with $\mathrm{C}-\mathrm{H}$ bonds in the gas phase.

Making sense of this data is difficult in the absence of a suitable method for simultaneous analysis of many CID experiments. However, this application is a paradigmatic example of the ability of EDESI-MS to make data interpretation simple and intuitive (Figure 3). Comparing the contour plot to the three separate spectra, it is obvious how much data is discarded by just taking snapshots of the CID process. The contour plot shows precisely how many $\mathrm{CO}$ ligands must be removed (through multiple energetic collisions in the source region) before a gas-phase reaction occurs. It is quite clear that at least three CO ligands must be lost before one 1-hexene molecule can react with the activated cluster. Three series of ions are present, each forming a sequence running from bottom right to top left. The lowest series consists of $\left[\mathrm{H}_{3} \mathrm{Ru}_{4}(\mathrm{CO})_{n}\right]^{-}(n=0-12)$, with the next two series consisting of species resulting from the addition of one $\left[\mathrm{H}_{3} \mathrm{Ru}_{4}(\mathrm{CO})_{n}\left(\mathrm{C}_{6} \mathrm{H}_{m}\right)\right]^{-}(n=0-9 ; m=2-12)$ or two $\left[\mathrm{H}_{3} \mathrm{Ru}_{4}(\mathrm{CO})_{n}\left(\mathrm{C}_{12} \mathrm{H}_{m}\right)\right]^{-}(n=0-8 ; m=6-24)$ equivalents of 1-hexene, with traces of a third molecule adding at higher cone voltages. There are small amounts of the first and second hexene adducts after loss of only two or three CO groups, but they are considerably less intense than after loss of three and four COs.

Some interesting features of the map can be analyzed in more detail by the application of MS/MS. For example, upon selection of the peak at $742 \mathrm{~m} / \mathrm{z}$, $\left[\mathrm{H}_{3} \mathrm{Ru}_{4}(\mathrm{CO})_{9}\left(\mathrm{C}_{6} \mathrm{H}_{8}\right)\right]^{-}$(the first ion formed by a gasphase reaction) and fragmentation by CID with Ar in the collision cell, up to three molecules of $\mathrm{H}_{2}$ are lost from the cluster. This process is clearly visible in the MS/MS product ion spectrum (see supporting information) where the loss of 2,4 , and $6 \mathrm{~m} / z$ from the precursor ion is observed. Because a maximum of one $\mathrm{H}_{2}$ could come from the three original hydride ligands on the metal cluster, this observation points to the facile nature of the $\mathrm{C}-\mathrm{H}$ activation process. The 1-hexene can be removed from the cluster once bound, but only if minimal $\mathrm{H}_{2}$ loss has occurred; this only occurs to a very small extent with $-\mathrm{CO}$ and $-\mathrm{H}_{2}$ far preferred.

Two reactions that we looked for very carefully in the MS/MS were the reductive elimination of hexane, $\mathrm{C}_{6} \mathrm{H}_{14}$, or hexanal, $\mathrm{C}_{6} \mathrm{H}_{13} \mathrm{CHO}$. Observation of these neutral losses (86 and $114 \mathrm{Da}$, respectively) would indicate that gas-phase hydrogenation or hydroformylation had occurred:

$$
\begin{aligned}
& \text { Hydrogenation: }\left[\mathrm{H}_{3} \mathrm{Ru}_{4}(\mathrm{CO})_{9}\left(\mathrm{C}_{6} \mathrm{H}_{12}\right)\right]^{-} \\
& \quad \rightarrow\left[\mathrm{HRu}_{4}(\mathrm{CO})_{9}\right]^{-}+\mathrm{C}_{6} \mathrm{H}_{14}
\end{aligned}
$$

Hydrogenation: $\left[\mathrm{H}_{3} \mathrm{Ru}_{4}(\mathrm{CO})_{9}\left(\mathrm{C}_{6} \mathrm{H}_{12}\right)\right]$

$$
\rightarrow\left[\mathrm{HRu}_{4}(\mathrm{CO})_{8}\right]^{-}+\mathrm{C}_{6} \mathrm{H}_{13} \mathrm{CHO}
$$

However, neither of these reactions appeared to occur. The most obvious reason for this is that insertion of the alkene into the $\mathrm{Ru}-\mathrm{H}$ bond (followed by, for hydroformylation, insertion of $\mathrm{CO}$ into the $\mathrm{Ru}-\mathrm{C}$ bond) must happen in order for reductive elimination to occur; and insertion reactions are favored by high pressure. Furthermore, apparently $\mathrm{C}-\mathrm{H}$ activation and elimination of $\mathrm{H}_{2}$ occur extremely quickly, a process that, again, would require a pressure of $\mathrm{H}_{2}$ to overcome. 


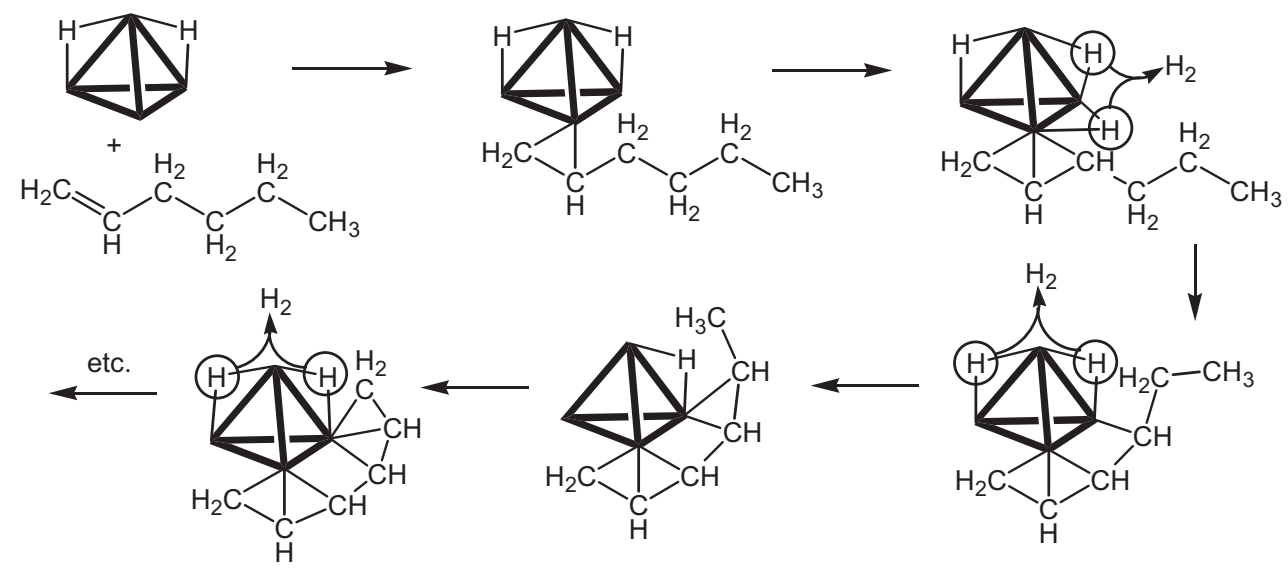

Scheme 1. Repeated intramolecular $\mathrm{C}-\mathrm{H}$ activation of 1-hexene, induced by ligand loss $\left(\mathrm{CO}\right.$ or $\left.\mathrm{H}_{2}\right)$ from the metal cluster. $\mathrm{CO}$ ligands are not shown for clarity. All cluster compounds carry a $1^{-}$charge.

The intramolecular $\mathrm{C}-\mathrm{H}$ activation of 1-hexene that we do observe could happen in an enormous number of different ways, given the large number of $\mathrm{C}-\mathrm{H}$ bonds and the presence of multiple metal centers; just one possibility is outlined in Scheme $\mathbf{1}$.

Cyclopentene also reacted readily with $\left[\mathrm{H}_{3} \mathrm{Ru}_{4}(\mathrm{CO})_{n}\right]^{-}$, with up to four equivalents of cyclopentene adding to the cluster (supporting information). Just as in the case of 1-hexene, extensive $\mathrm{C}-\mathrm{H}$ activation and $\mathrm{H}_{2}$ loss occurred, raising the interesting possibility that a cyclopentadienyl ligand might be generated through rearrangement. Cyclopentadienyl ligands are generally resistant to CID, however, with other ligands being eliminated preferentially, had a cyclopentadienyl ligand been generated, we would have expected to observe unusual stability for ions with $\geq 5 \mathrm{H}$; however, we observed no such trend. This result may indicate that multiple metal centers are involved in the $\mathrm{C}-\mathrm{H}$ activation. Also, given the high degree of $\mathrm{H}_{2}$ loss, it is not possible to rule out $\mathrm{C}-\mathrm{C}$ bond activation either. The slightly higher extent of reaction for cyclopentene over 1-hexene may simply be steric in nature.

\section{Silanes}

Silicon-hydrogen bonds are reactive towards metal compounds, undergoing facile oxidative addition to unsaturated metal centers. As such, they are good candidates for gas-phase reactions because of the availability of many volatile compounds containing the $\mathrm{Si}-\mathrm{H}$ bond. Triethylsilane, $\mathrm{HSi}\left(\mathrm{C}_{2} \mathrm{H}_{5}\right)_{3}$, proved highly reactive (Figure 4). Loss of just one $\mathrm{CO}$ ligand from $\left[\mathrm{H}_{3} \mathrm{Ru}_{4}(\mathrm{CO})_{12}\right]^{-}$prompted the immediate formation of $\left[\mathrm{H}_{4} \mathrm{Ru}_{4}(\mathrm{CO})_{11}\left(\mathrm{SiEt}_{3}\right)\right]^{-}$, and loss of two CO ligands generated $\left[\mathrm{H}_{5} \mathrm{Ru}_{4}(\mathrm{CO})_{10}\left(\mathrm{SiEt}_{3}\right)_{2}\right]^{-}$. Further CID of both of these products (MS/MS studies, see supporting

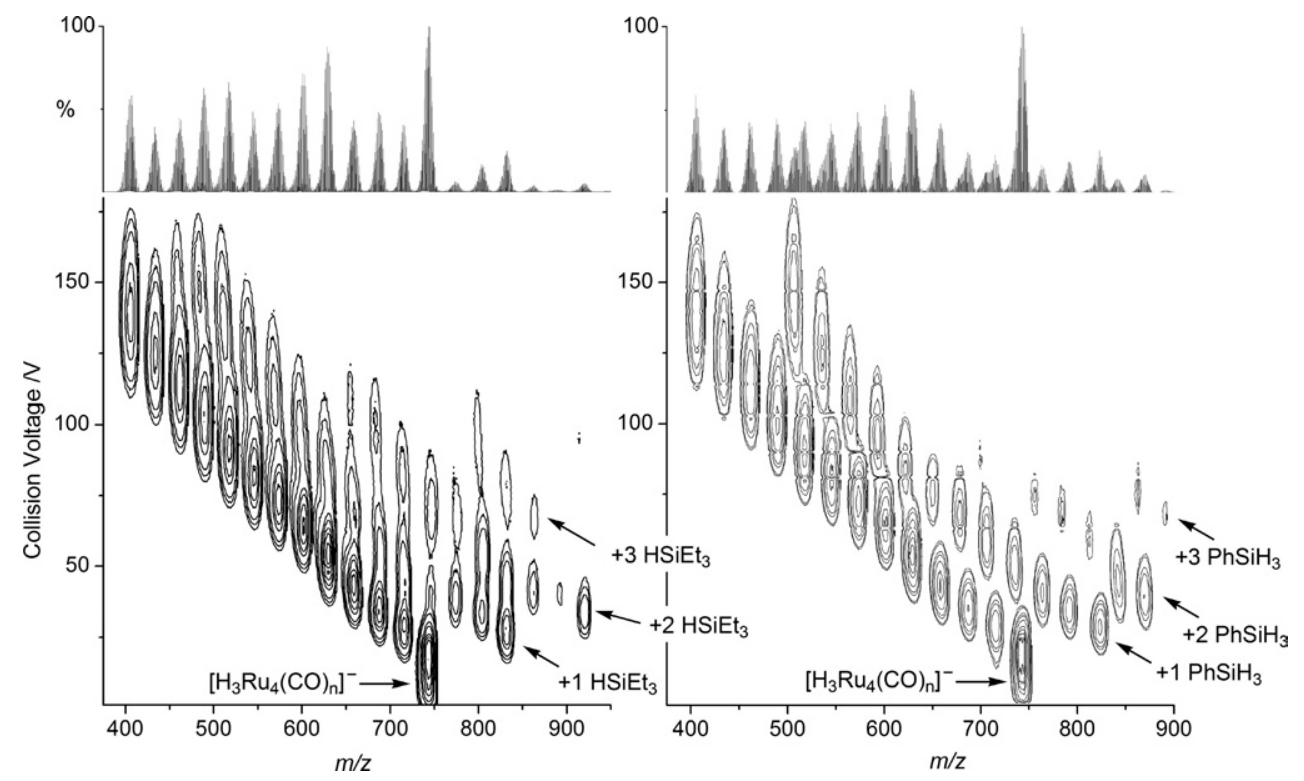

Figure 4. The negative-ion EDESI-MS of $\left[\mathrm{H}_{3} \mathrm{Ru}_{4}(\mathrm{CO})_{12}\right]^{-}$, collected in the presence of triethylsilane (left) and phenylsilane (right). Peak assignments are available in the supporting information. 
information) results in reductive elimination of $\mathrm{HSiEt}_{3}$ and the reintensifying of the $\left[\mathrm{H}_{3} \mathrm{Ru}_{4}(\mathrm{CO})_{n}\right]^{-}$series.

Reactivity with phenylsilane showed the rapid addition of $\mathrm{PhSiH}_{3}$ after loss of one $\mathrm{CO}$ ligand. This product ion, however, is more stable than the triethylsilane analogue, and in MS/MS experiments loss of CO is preferred to the reductive elimination of the silane. The MS/MS experiment shows that $\mathrm{H}_{2}$ loss is facile, suggesting $\mathrm{Si}-\mathrm{H}$ bond activation occurs even more readily than the $\mathrm{C}-\mathrm{H}$ bond activation observed in the hydrocarbon examples, as peak assignment of the highest mass ion to add two equivalents of $\mathrm{PhSiH}_{3}$ requires the elimination of three $\mathrm{H}_{2}$ molecules (see supporting information).

The presence of two silyl ligands on the cluster is interesting, because reductive elimination of a disilane is possible-gas-phase dehydrocoupling of two silanes:

$$
\begin{aligned}
& \text { Dehydrocoupling: }\left[\mathrm{H}_{5} \mathrm{Ru}_{4}(\mathrm{CO})_{10}\left(\mathrm{SiEt}_{3}\right)_{2}\right]^{-} \\
& \quad \rightarrow\left[\mathrm{H}_{5} \mathrm{Ru}_{4}(\mathrm{CO})_{10}\right]^{-}+\mathrm{Et}_{6} \mathrm{SiSiEt}_{3}
\end{aligned}
$$

As for a gas-phase catalytic reaction, we observed no evidence pointing towards reductive elimination of disilanes (see supporting information), indicating that the bound silyl groups are remote from one another, a reasonable assumption on steric grounds alone. As was observed in the case of hexene, rapid loss of $\mathrm{H}_{2}$ and $\mathrm{CO}$ seems to inhibit any other sort of reductive elimination or ligand loss.

\section{Arenes}

Toluene is another unsaturated hydrocarbon but one which forms complexes with transition metals in quite a different way to alkenes. The normal bonding mode is not $\eta^{2}$ - or $\eta^{4}$ - but rather $\eta^{6}-\mathrm{C}_{7} \mathrm{H}_{8}$, where all six carbon atoms of the aromatic ring are bound to the metal. As such, aromatic rings occupy three coordination sites of a metal and are six-electron donors. Many complexes are known where three $\mathrm{CO}$ ligands are replaced by an arene, the classic examples being $\mathrm{Cr}(\mathrm{CO})_{6}, \mathrm{Cr}(\mathrm{CO})_{3}\left(\eta^{6}{ }^{6}\right.$ $\left.\mathrm{C}_{6} \mathrm{H}_{6}\right)$, and $\mathrm{Cr}\left(\eta^{6}-\mathrm{C}_{6} \mathrm{H}_{6}\right)_{2}$ [60]. Numerous clusters with arene ligands are also known, such as $\mathrm{Ru}_{6} \mathrm{C}(\mathrm{CO})_{14}\left(\eta^{6}{ }^{6}-\right.$ $\left.\mathrm{C}_{6} \mathrm{H}_{6}\right)$ or $\mathrm{Os}_{3}(\mathrm{CO})_{9}\left(\eta^{6}-\mathrm{C}_{6} \mathrm{H}_{6}\right)$, and in some cases the arene takes up a binding mode in which the ligand is bound to a triangular metal face, as in $\operatorname{Ru}_{3}(\mathrm{CO})_{9}\left(\mu_{3}-\eta \eta^{2}\right.$ : $\left.\eta^{2}: \eta^{2}-\mathrm{C}_{6} \mathrm{H}_{6}\right)$ [61]. As such, we were interested to find out at what degree of unsaturation of the cluster an aromatic molecule would bind. The spectrum (see supporting information) revealed that toluene was certainly less reactive than the alkenes, with substantially lower intensities for all reaction products and only trace quantities of double reactivity (the addition of two toluene molecules to the cluster). Toluene appears to react appreciably with $\left[\mathrm{H}_{3} \mathrm{Ru}_{4}(\mathrm{CO})_{n}\right]^{-}$only when $n \leq 7$, i.e., at least five $\mathrm{CO}$ ligands have been lost from the cluster. The fact that extra CO ligands need to be lost beyond what would be expected electronically is perhaps not surprising, as the removal of CO ligands is expected to be from the cluster as a whole rather than from three adjacent coordination sites becoming free on a single metal center; as such, the increased reactivity of the unsaturated compound is likely to be diluted by the presence of multiple metal centers. Chlorobenzene was even less reactive than toluene, reacting with $\left[\mathrm{H}_{3} \mathrm{Ru}_{4}(\mathrm{CO})_{n}\right]^{-}$only when $n \leq 1$, i.e., at least $11 \mathrm{CO}$ ligands being lost from the cluster (see supporting information).

\section{Alkane}

The high level of intramolecular $\mathrm{C}-\mathrm{H}$ activation that occurred during our studies of the reactivity of 1hexene and cyclopentene with $\left[\mathrm{H}_{3} \mathrm{Ru}_{4}(\mathrm{CO})_{n}\right]^{-}$led us to consider whether an ion this reactive would participate in the more challenging intermolecular $\mathrm{C}-\mathrm{H}$ activation [62]. An attempt with pentane as the reactive gas showed that indeed this process did occur, provided the cluster was sufficiently unsaturated. Pentane reacted with $\left[\mathrm{HRu}_{4}(\mathrm{CO})_{5}\right]^{-}$(i.e., only after loss of seven $\mathrm{CO}$ ligands) to generate $\left[\mathrm{HRu}_{4}(\mathrm{CO})_{5}\left(\mathrm{C}_{5} \mathrm{H}_{7}\right)\right]^{-}$(see supporting information). This product ion has already undergone extensive intramolecular $\mathrm{C}-\mathrm{H}$ activation and $\mathrm{H}_{2}$ loss, and is subjected to further $\mathrm{H}_{2}$ and $\mathrm{CO}$ elimination to form the carbonyl-free cluster core $\left[\mathrm{HRu}_{4}\left(\mathrm{C}_{5}\right)\right]^{-}$. The reactivity between $\left[\mathrm{HRu}_{4}(\mathrm{CO})_{n}\right]^{-}(n<5)$ and pentane is in contrast to Ridge's report that anionic clusters were unreactive towards cyclohexane [24], but is consistent with the reactivity of $\left[\mathrm{CoRu}_{3}\right]^{-}$towards methane that we observed in earlier FTICR studies [26].

\section{Oxygen}

The reaction of the cluster with molecular oxygen produced perhaps the most dramatic results (Figure 5). No reaction appears to occur until four $\mathrm{CO}$ ligands are removed via CID, at which point the remaining $C O$ ligands are very rapidly replaced with oxygen and broken down into heavily oxidized tri-, di-, and mononuclear ruthenium complexes. The most stable product in this oxidation is the $\left[\mathrm{RuO}_{3}\right]^{-}$ion with trace amounts of $\left[\mathrm{RuO}_{2}\right]^{-}$and $\left[\mathrm{RuO}_{4}\right]^{-}$, and to our knowledge this represents the first observation of $\mathrm{Ru}(\mathrm{V})$ and $\mathrm{Ru}(\mathrm{VII})$ in the gas phase.

The fact that oxidation results in rapid $\mathrm{CO}$ loss is unsurprising considering that $\mathrm{CO}$ is a good ligand only for low oxidation state metals [61]. Fragmentation to lower nuclearity species is probably via loss of $\operatorname{Ru}_{n} \mathrm{O}_{m}$ ( $n=1-3 ; m=1-6)$; MS/MS studies on selected ions such as $\left[\mathrm{Ru}_{4} \mathrm{O}_{4}\right]^{-}$reveal formation of $\left[\mathrm{RuO}_{2}\right]^{-}$, implicating loss of $\mathrm{Ru}_{3} \mathrm{O}_{2}$. However, $\left[\mathrm{RuO}_{3}\right]^{-}$(the ultimate product ion in the EDESI-MS) is never observed as a product ion in MS/MS studies (CID using $\mathrm{Ar}$ in the collision cell), which suggests that formation of this species requires fast fragmentation following a final addition of $\mathrm{O}_{2}$ to the precursor ion. 


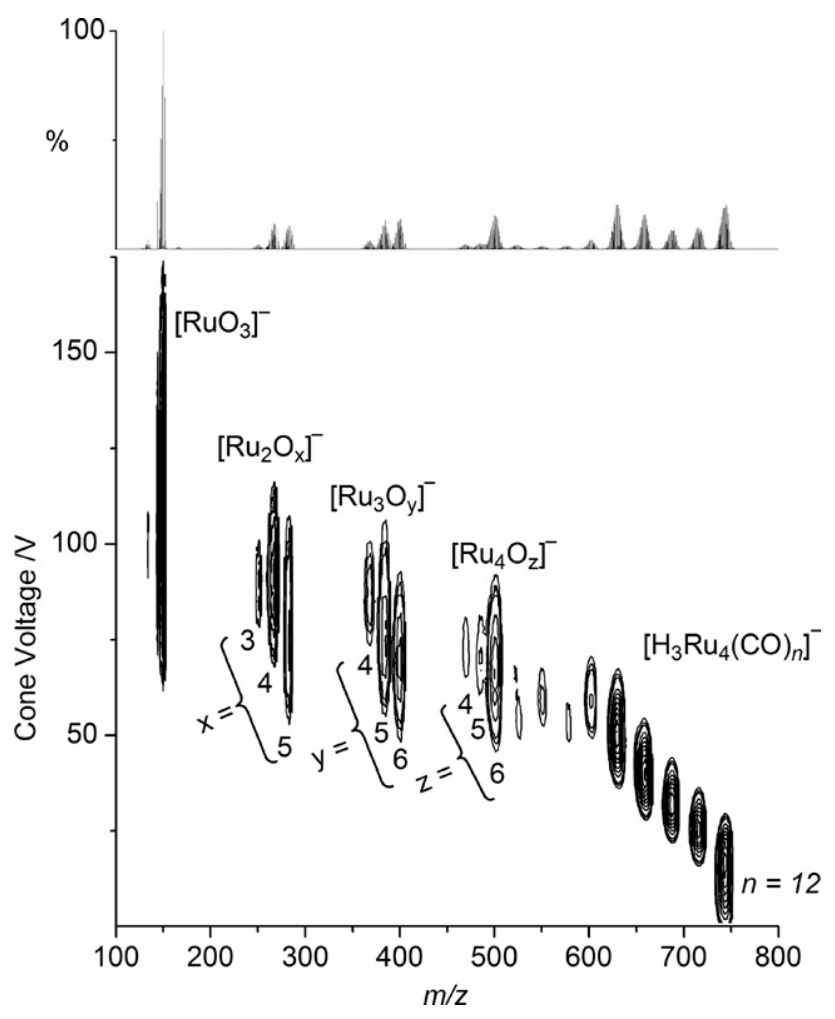

Figure 5. The negative-ion EDESI-MS of $\left[\mathrm{H}_{3} \mathrm{Ru}_{4}(\mathrm{CO})_{12}\right]^{-}$, collected in the presence of oxygen. Peak assignments are available in the supporting information.

Gas-phase studies with molecular oxygen have typically been done in the positive ion mode with metals coordinated by chelating ligands such as bipyridine [63]. Under CID conditions these oxygenated species generally lose the $\mathrm{O}_{2}$ moiety; however, it is not possible to determine whether the oxo group is bound in a coordinate fashion, $\mathrm{M}\left(\mathrm{O}_{2}\right)$, or whether an electron-transfer process has occurred to reduce the oxygen and oxidize the metal with two oxygen atoms bound $\mathrm{O}=\mathrm{M}=\mathrm{O}$. Our results suggest that electron-transfer from the very low valent ruthenium atoms to the $\mathrm{O}_{2}$ groups occurs to a significant degree, accounting for the very abrupt loss of all the remaining $\mathrm{CO}$ ligands from the cluster.

\section{Conclusions}

A simple, inexpensive method of introducing gases or volatile liquids for reaction with gas-phase ions using a electrospray ionization mass spectrometer has been demonstrated. The reactivity of any gas-phase ion towards any reasonably volatile molecule may be examined simply and easily by means of EDESI-MS. Vacant coordination sites may be generated on the ions by collision-induced dissociation, simulating the effect of thermal activation and enhancing the reactivity of ions to the point that they will undergo otherwise unfavorable reactions. This process has been illustrated for the reaction of $\left[\mathrm{H}_{3} \mathrm{Ru}_{4}(\mathrm{CO})_{n}\right]^{-}(n=0-12)$ with alkenes, arenes, alkanes, silanes, and oxygen, each of which displays quite different reactivity. None react with the unactivated, coordinatively saturated cluster $\left[\mathrm{H}_{3} \mathrm{Ru}_{4}(\mathrm{CO})_{12}\right]^{-}$, but removal of the $\mathrm{CO}$ ligands makes it reactive towards first silanes (at one CO ligand removed), hexene and cyclopentene (two and three), oxygen (four), toluene (five), pentane (at seven CO ligands removed), and chlorobenzene (eleven). The gas-phase reactivity bears most relevance to solution chemistry when the extent of activation is lowest, i.e., the fewest ligands are removed from the cluster by CID. It is relatively easy to remove one or two $\mathrm{CO}$ ligands from a cluster in solution by the application of heat or light or by chemical means (e.g., oxidation using $N$-trimethylamine oxide), but the conditions required to remove more than a couple of ligands would be expected to result in extensive decomposition of the cluster. Reductive elimination of alkanes, aldehydes, or disilanes-the molecules of most relevance to classic organometallic catalytic reactions-was not observed. Further CID in the collision cell suggested that multiple reductive elimination of dihydrogen (presumably following repeated intramolecular $\mathrm{C}-\mathrm{H}$ activation) inhibited any reactions of special relevance to catalysis.

The application of this method is expected to come when chemists want to rapidly investigate the reactivity of a new compound (e.g., a potential catalyst) against a wide range of substrates. Instead of conducting a large number of conventional reactions, a compound may simply be investigated by ESI-MS under suitable conditions that generate a single vacant coordination site (i.e., the conditions most easily simulated in solution). Introduction of various volatile substrates of interest via the experimental setup described herein will allow investigators to get a rapid, qualitative indication of reactivity, and determine which reactions are worth pursuing in conventional fashion.

\section{Acknowledgments}

J. S. M. thanks Natural Sciences and Engineering Research Council (NSERC) of Canada, the Canada Foundation for Innovation (CFI) and the British Columbia Knowledge Development Fund (BCKDF), and the University of Victoria for instrumentation and operational funding. S.K. thanks NSERC for an Undergraduate Student Research Award.

\section{References}

1. O'Hair, R. A. J.; Khairallah, G. N. Gas Phase Ion Chemistry of Transition Metal Clusters: Production, Reactivity, and Catalysis. J. Clust. Sci. 2004, 15, 331-363.

2. Armentrout, P. B. Reactions and Thermochemistry of Small Transition Metal Cluster ions. Annu. Rev. Phys. Chem. 2001, 52, 423-461.

3. Plattner, D. A. Electrospray Mass Spectrometry Beyond Analytical Chemistry: Studies of Organometallic Catalysis in the Gas Phase. Int. J. Mass Spectrom. 2001, 207, 125-144.

4. Bohme, D. K.; Schwarz, H. Gas-Phase Catalysis by Atomic and Cluster Metal Ions: The Ultimate Single-Site Catalysts. Angew. Chem. Int. Ed. 2005, 44, 2336-2354.

5. Gerdes, G.; Chen, P. Comparative Gas-Phase and Solution-Phase Investigations of the Mechanism of C-H Activation by $\left[(\mathrm{N}-\mathrm{N}) \mathrm{Pt}\left(\mathrm{CH}_{3}\right)(\mathrm{L})\right]^{+}$. Organometallics 2003, 22, 2217-2225.

6. Gerdes, G.; Chen, P. Response to: “C-H Activation by Platinum(II) What Do Gas-Phase Studies Tell Us About the Solution-Phase Mechanism?" Organometallics 2006, 25, 809-811. 
7. Labinger, J. A.; Bercaw, J. E.; Tilset, M. C-H Activation by Platinum(II): What Do Gas-Phase Studies Tell Us About the Solution-Phase Mechanism? Organometallics 2006, 25, 805-808.

8. Zemski, K. A.; Justes, D. R.; Castleman, A. W. Jr. Studies of Metal Oxide Clusters: Elucidating Reactive Sites Responsible for the Activity of Transition Metal Oxide Catalysts. J. Phys. Chem. B 2002, 106, 6136-6148.

9. Jackson, P.; Harvey, J. N.; Schroder, D.; Schwarz, H. Structure and Reactivity of the Prototype Iron-Oxide Cluster $\mathrm{Fe}_{2} \mathrm{O}_{2}{ }^{+}$. Int. J. Mass Spectrom. 2001, 204, 233-245.

10. Gehret, O.; Irion, M. P. O-Atom Transfer to $\mathrm{Fe}_{n}{ }^{+}$clusters $(n=2-10)$ from $\mathrm{O}_{2}, \mathrm{~N}_{2} \mathrm{O}$, and $\mathrm{CO}_{2}$ : "Micro-Oxides of Iron". Chem. Eur. J. 1996, 2, 598-603.

11. Bell, R. C.; Zemski, K. A.; Castleman, A. W. Size-Specific Reactivities of Vanadium Oxide Cluster Cations. J. Clust. Sci. 1999, 10, 509-524.

12. Khairallah, G. N.; O'Hair, R. A. J. Gas-Phase Synthesis of $\left[\mathrm{Ag}_{4} \mathrm{H}\right]^{+}$and its mediation of the $\mathrm{C}-\mathrm{C}$ Coupling of Allyl Bromide. Angew. Chem. Int. Ed. 2005, 44, 728-731.

13. Harvey, J. N.; Schroder, D.; Schwarz, H. Generation of Mixed Iron Chalcogenide Clusters $\mathrm{MFeX}_{\mathrm{n}}{ }^{+}(\mathrm{M}=\mathrm{V}, \mathrm{Fe} ; \mathrm{X}=\mathrm{O}, \mathrm{S} ; \mathrm{N}=2,3)$ in the Gas Phase. Inorg. Chim. Acta. 1998, 273, 111-115.

14. Elnakat, J. H.; Dance, I. G.; Fisher, K. J.; Rice, D.; Willett, G. D. Laser-Ablation FTICR Mass-Spectrometry of Metal Sulfides-Gaseous Anionic $\left[\mathrm{Ni}_{\mathrm{x}} \mathrm{S}_{\mathrm{y}}\right]$ Clusters. J. Am. Chem. Soc. 1991, 113, 5141-5148.

15. Lightstone, J. M.; Patterson, M. J.; White, M. G. Reactivity of the $\mathrm{M}_{4} \mathrm{~S}_{6}{ }^{+}$ $(\mathrm{M}=\mathrm{Mo}, \mathrm{W})$ Cluster with $\mathrm{CO}$ and $\mathrm{NH}_{3}$ in the Gas Phase: An experimental and DFT study. Chem. Phys. Lett. 2005, 413, 429-433.

16. Lightstone, J. M.; Patterson, M. J.; Liu, P.; White, M. G. Gas-Phase Reactivity of the $\mathrm{Ti}_{8} \mathrm{C}_{12}{ }^{+}$met-car with Triatomic Sulfur-Containing Molecules: $\mathrm{CS}_{2}, \mathrm{SCO}$, and $\mathrm{SO}_{2}$. J. Phys. Chem. A 2006, 110, 3505-3513.

17. Koszinowski, K.; Schroeder, D.; Schwarz, H. Reactions of PlatinumCarbene Clusters $\mathrm{Pt}_{n} \mathrm{CH}_{2}{ }^{+}(n=1-5)$ with $\mathrm{O}_{2}, \mathrm{CH}_{4}, \mathrm{NH}_{3}$, and $\mathrm{H}_{2} \mathrm{O}$ : Coupling Processes versus Carbide Formation. Organometallics 2003, 22, 3809-3819.

18. Khairallah, G. N.; O'Hair, R. A. J.; Bruce, M. I. Gas-Phase Synthesis and Reactivity of Binuclear Gold Hydride Cations, $\left(\mathrm{R}_{3} \mathrm{PAu}\right)_{2} \mathrm{H}^{+}(\mathrm{R}=\mathrm{Me}$ and Ph). Dalton Trans. 2006, 3699-3707.

19. Waters, T.; O'Hair, R. A. J.; Wedd, A. G. Catalytic Gas Phase Oxidation of Methanol to Formaldehyde. J. Am. Chem. Soc. 2003, 125, 3384-3396.

20. Waters, T.; O'Hair, R. A. J.; Wedd, A. G. Gas-Phase Reactivity of Heterobinuclear Oxometalate Anions $\left[\mathrm{CrMoO}_{6}(\mathrm{OR})\right]^{-},\left[\mathrm{CrWO}_{6}(\mathrm{OR})\right]^{-}$, and $\left[\mathrm{MoWO}_{6}(\mathrm{OR})\right]^{-}\left(\mathrm{R}=\mathrm{H},{ }^{\mathrm{n}} \mathrm{Bu}\right)$. Inorg. Chem. 2005, 44, 3356-3366.

21. Deng, H. T.; Kerns, K. P.; Castleman, A. W. Formation, Structures, and Reactivities of Niobium Oxide Cluster Ions. J. Phys. Chem. 1996, 100, $13386-13392$.

22. Fialko, E. F.; Kikhtenko, A. V.; Goncharov, V. B.; Zamaraev, K. I. Similarities between Reactions of Methanol with $\mathrm{Mo}_{\mathrm{x}} \mathrm{O}_{\mathrm{y}}{ }^{+}$in the Gas Phase and Over Real Catalysts. J. Phys. Chem. B 1997, 101, 5772-5773.

23. Freas, R. B.; Ridge, D. P. Effect of a Carbonyl Ligand on the rReactivity of Cobalt(2+) Ion Toward Alkanes. J. Am. Chem. Soc. 1984, 106, 825-826.

24. Pan, Y. H.; Ridge, D. P. Reactions of Cyclohexane with Tetrairidium Carbonyl Cluster Ions: Electronic Criteria for Carbon-Hydrogen Bond Activation in Alkanes. J. Phys. Chem. 1989, 93, 3375-8.

25. Butcher, C. P. G.; Dyson, P. J.; Johnson, B. F. G.; Khimyak, T.; McIndoe, J. S. Fragmentation of Transition Metal Carbonyl Cluster Anions: Structural Insights from Mass Spectrometry. Chem. Eur. J. 2003, 9, 944-950.

26. Butcher, C. P. G.; Dinca, A.; Dyson, P. J.; Johnson, B. F. G.; LangridgeSmith, P. R. R.; McIndoe, J. S. A Strategy for Generating Naked-Metal Clusters for Gas-Phase Reactivity Studies by FTICR-MS. Angew. Chem. Int. Ed. 2003, 42, 5752-5755.

27. Jackson, P. F.; Johnson, B. F. G.; Lewis, J.; McPartlin, M.; Nelson, W. J. H. $\left[\mathrm{H}_{3} \mathrm{Ru}_{4}(\mathrm{Co})_{12}\right]^{-}$X-Ray Crystallographic Determination of Two Structural Isomers. J. Chem. Soc. Chem. Commun. 1978, 920-921.

28. Dyson, P. J.; Hearley, A. K.; Johnson, B. F. G.; McIndoe, J. S.; LangridgeSmith, P. R. R.; Whyte, C. Combining Energy-Dependent Electrospray Ionization with Tandem Mass Spectrometry for the Analysis of Inorganic Compounds. Rapid Commun. Mass Spectrom. 2001, 15, 895-897.

29. Butcher, C. P. G.; Dyson, P. J.; Johnson, B. F. G.; Langridge-Smith, P. R. R.; McIndoe, J. S.; Whyte, C. On the Use of Breakdown Graphs Combined with Energy-Dependent Mass Spectrometry to Provide a Complete Picture of Fragmentation Processes. Rapid Commun. Mass Spectrom. 2002, 16, 1595-1598.

30. Husheer, S. L. G.; Forest, O.; Henderson, M.; McIndoe, J. S. EDit: A Computer Program to Assist in the Presentation of Energy-Dependent Mass Spectra. Rapid Commun. Mass Spectrom. 2005, 19, 1352-1354.

31. Freiser, B. S. Gas-Phase Metal Ion Chemistry. J. Mass Spectrom. 1996, 31 , 703-715.

32. Chen, P. Electrospray Ionization Tandem Mass Spectrometry in HighThroughput Screening of Homogeneous Catalysts. Angew. Chem. Int. Ed. 2003, 42, 2832-2847.

33. Gerlich, D. Experimental Investigations of Ion-Molecule Reactions Relevant to Interstellar Chemistry. J. Chem. Soc. Faraday Trans. 1993, 89, 2199-2208.

34. O'Hair, R. A. J. The 3D Quadrupole Ion Trap Mass Spectrometer as a Complete Chemical Laboratory for Fundamental Gas-Phase Studies of Metal Mediated Chemistry. Chem. Commun. 2006, 1469-1481.

35. Schroeder, D.; Weiske, T.; Schwarz, H. Dissociation Behavior of $\mathrm{Cu}(\text { urea })^{+}$Complexes Generated by Electrospray Ionization. Int. J. Mass Spectrom. 2002, 219, 729-738.
36. Trage, C.; Diefenbach, M.; Schroder, D.; Schwarz, H. Innocent and Less-Innocent Solvent Ligands: A Systematic Investigation of Cationic Iron Chloride/Alcohol Complexes by Electrospray Ionization Mass Spectrometry Complemented by DFT Calculations. Chem. Eur. J. 2006, $12,2454-2464$.

37. Fenn, J. B.; Mann, M.; Meng, C. K.; Wong, S. F. Whitehouse, C. M. Electrospray Ionization for Mass Spectrometry of Large Biomolecules. Science 1989, 246, 64-71.

38. Henderson, W.; McIndoe, J. S. Mass Spectrometry of Inorganic and Organometallic Compounds: Tools, Techniques, Tips; Wiley: Chichester, 2005; p. 90.

39. Sakamoto, S.; Fujita, M.; Kim, K.; Yamaguchi, K. Characterization of Self-Assembling Nano-Sized Structures by Means of Coldspray Ionization Mass Spectrometry. Tetrahedron 2000, 56, 955-964.

40. Brayshaw, S. K.; Ingleson, M. J.; Green, J. C.; Raithby, P. R.; KociokKohn, G.; McIndoe, J. S.; Weller, A. S. Holding onto lots of hydrogen: A 12-Hydride Rhodium Cluster that Reversibly Adds Two Molecules of $\mathrm{H}_{2}$. Angew. Chem. Int. Ed. 2005, 44, 6875-6878.

41. Schneider, B. B.; Chen, D. D. Y. Collision-Induced Dissociation of Ions Within the Orifice-Skimmer Region of an Electrospray Mass Spectrometer. Anal. Chem. 2000, 72, 791-799.

42. Spence, T. G.; Burns, T. D.; Posey, L. A. Controlled Synthesis of Transition-Metal Ion Complex Solvent Clusters by Electrospray. J. Phys. Chem. A 1997, 101, 139-144.

43. Ikonomou, M. G.; Blades, A. T.; Kebarle, P. Electrospray Ion Spray-a Comparison of Mechanisms and Performance. Anal. Chem. 1991, 63, 1989-1998.

44. Spence, T. G.; Trotter, B. T.; Burns, T. D.; Posey, L. A. Metal-to-Ligand Charge Transfer in the Gas-Phase Cluster Limit. J. Phys. Chem. A 1998, 102, 6101-6106.

45. Schlosser, G.; Takats, Z.; Vékey, K. Formation of Solvated Ions in the Atmospheric Interface of an Electrospray Ionization Triple-Quadrupole Mass Spectrometer. J. Mass Spectrom. 2003, 38, 1245-1251.

46. McQuinn, K.; Hof, F.; McIndoe, J. S. Direct Observation of Ion Evaporation from a Triply Charged Nanodroplet. Chem. Commun. 2007, 4099-4101.

47. McQuinn, K.; McIndoe, L. S.; Hof, F. Insights into the Post-Translational Methylation of Arginine from Studies of Guanidinium-Water Nanodroplets. Chem. Eur. J. 2008, 14, 6483-6489.

48. Chisholm, D. M.; McIndoe, J. S. Charged Ligands for Catalyst Immobilization and Analysis. Dalton Trans. 2008, 3933-3945.

49. Johnson, B. F. G.; McIndoe, J. S. Spectroscopic and Mass Spectrometric Methods for the Characterization of Metal Clusters. Coord. Chem. Rev. 2000, 200/202, 901-932

50. Ungermann, C.; Landis, V.; Moya, S. A.; Cohen, H.; Walker, H.; Pearson, R. G.; Rinker, R. G.; Ford, P. C. Homogeneous Catalysis of the Water Gas Shift Reaction by Ruthenium and Other Metal Carbonyls. Studies in Alkaline Solutions. J. Am. Chem. Soc. 1979, 101, 5922-5929.

51. Bricker, J. C.; Nagel, C. C.; Shore, S. G. Reactivities of Ruthenium Cluster Anions: Implications for Catalysis of the Water-Gas Sshift Reaction. J. Am. Chem. Soc. 1982, 104, 1444-1445.

52. Schmidt, G. F.; Reiner, J.; Suess-Fink, G. Catalytic Hydrogenation and Hydrocoupling of Acetic Acid Amides and Esters with the Cluster Anion $\left[\mathrm{H}_{3} \mathrm{Ru}_{4}(\mathrm{CO})_{12}\right]^{-}$as catalyst. J. Organomet. Chem. 1988, 355, 379-384.

53. Suess-Fink, G.; Herrmann, G.; Schmidt, G. F. Novel Catalytic Applications of Anionic Ruthenium Clusters in Isocyanate Chemistry. Polyhedron 1988, 7, 2341-2344.

54. Doi, Y.; Koshizuka, K.; Keii, T. Metal Cluster Catalysis. Kinetics and Mechanism of the Catalytic Hydrogenation of Ethylene by the Ruthenium Cluster Complex $\mathrm{H}_{4} \mathrm{Ru}_{4}(\mathrm{CO})_{12}$. Inorg. Chem. 1982, 21, 2732-2736.

55. Bhaduri, S.; Sharma, K.; Mukesh, D. Transfer Hydrogenation of Ketones with Dodecacarbonyltrihydridotetraruthenate $(-)$ as the Orecatalyst. J. Chem. Soc. Dalton Trans. 1993, 1191-1199.

56. Castiglioni, M.; Giordano, R.; Sappa, E. Metal Carbonyl Clusters in Homogeneous Catalysis. Hydrogenation and Isomerization of Cyclic Dienes in the Presence of $\left[\mathrm{H}_{4} \mathrm{Ru}_{4}(\mathrm{CO})_{12}\right],\left[\mathrm{H}_{2} \mathrm{Ru}_{4}(\mathrm{CO})_{13}\right]$ $\left[\mathrm{H}_{2} \mathrm{FeRu}_{3}(\mathrm{CO})_{13}\right]$, and $\left[\mathrm{Fe}_{2} \mathrm{Ru}(\mathrm{CO})_{12}\right]$. Identification of Organometallic Products and a Discussion of Their Role. J. Organomet. Chem. 1995, 491, 111-20.

57. Tominaga, K.-I.; Sasaki, Y. Ruthenium-Catalyzed One-Pot Hydroformylation of Alkenes Using Carbon Dioxide as a Reactant. J. Mol. Catal. A Chemical. 2004, 220, 159-165.

58. Farrer, N. J.; McDonald, R.; McIndoe, J. S. Proton Sponge Phosphines: Electrospray-Active Ligands. Dalton Trans. 2006, 4570-4579.

59. Dyson, P. J.; Johnson, B. F. G.; McIndoe, J. S.; Langridge-Smith, P. R. R. Energy-Dependent Electrospray Ionization Mass Spectrometry: Applications in Transition Metal Carbonyl Chemistry. Rapid Commun. Mass Spectrom. 2000, 14, 311-313

60. Crabtree, R. H. The Organometallic Chemistry of the Transition Metals, 3rd ed.; John Wiley and Sons: New York, 2001; p. 137.

61. Dyson, P. J.; McIndoe, J. S. Transition Metal Carbonyl Cluster Chemistry; Gordon and Breach: Amsterdam, 2000; p. 43.

62. Crabtree, R. H. The Organometallic Chemistry of Alkanes. Chem. Rev. 1985, 85, 245-269.

63. Molina-Svendsen, H.; Bojesen, G.; McKenzie, C. J. Gas-Phase Reactivity of Coordinatively Unsaturated Transition Metal Complex Ions Toward Molecular Oxygen. Inorg. Chem. 1998, 37, 1981-1983. 